\title{
ATTITUDES OF FEMALE STREET VENDORS TOWARDS HIV/AIDS IN VHEMBE DISTRICT OF SOUTH AFRICA
}

\author{
Olaniyi FC ${ }^{1 *}$, Tshitangano TG ${ }^{1}$, Tugli AK ${ }^{1}$, Amosu AM², Edokpayi JN ${ }^{3}$
}

${ }^{1}$ Department of Public Health, School of Health Sciences, University of Venda. ${ }^{2}$ Department of Public Health, School of Public and Allied Health, Babcock University, Nigeria. ${ }^{3}$ Department of Hydrology and Water Resources, School of Environmental Sciences, University of Venda.

"Corresponding Author E-mail: foluolaniyi@yahoo.com

\begin{abstract}
Background: The Human Immunodeficiency Virus (HIV) and Acquired Immunodeficiency Syndrome (AIDS) are still global health problems. This study was conducted to describe the attitudes of female street vendors (FSV) in Thohoyandou, Vhembe district, towards HIV/AIDS and those infected with the virus.

Materials and methods: A quantitative, cross-sectional survey design was adopted. Data were collected by means of a structured, self-administered questionnaire and analyzed using the Statistical Package for Social Sciences (SPSS) version 20.0 .

Results: Majority $(85.0 \%)$ of the participants had completed secondary education, $46.7 \%$ were single and $41.5 \%$ were aged 40 and above. Most of them (90.5\%) indicated that they would accept to do a voluntary HIV test. Fear of stigmatization ranked highest among the reasons given by those not in favour of testing. Whilst $91.0 \%$ of the participants reported that they can stay in the same house with a person who is HIV positive and $88.5 \%$ said they would not have sex in exchange for money, only $57.5 \%$ indicated that they would agree to take antiretroviral drugs if they tested positive in pregnancy. The level of education was found to be significantly associated (p-value $=0.000$ ) with the type of attitude shown towards HIV and those infected.

Conclusion: It is recommended that HIV information providers and health workers in South Africa pay more attention to enlightening women about the importance of taking

antiretroviral drugs in pregnancy to reduce the incidence of mother-to-child transmission of HIV.
\end{abstract}

Keywords: Attitude; female street vendors; HIV/AIDS; health workers, antiretroviral drugs.

\section{Introduction}

The Human Immunodeficiency Virus (HIV) causes the chronic disease, Acquired Immunodeficiency Syndrome (AIDS) which has remained a public menace despite the efforts being geared towards curtailing it. Globally, over 1.5 million AIDS-related deaths are recorded annually, more than 2 million new infections were recorded in 2013 and 36 million people are still living with the virus (Fowler, 2014; UNAIDS, 2014). In sub-Saharan Africa, 1.5 million new infections and 1.1 million AIDS-related deaths were recorded in 2013 while 24.7 million people are still living with the virus, making the region home to more than two-third of the world's HIV cases (UNAIDS, 2014).

South Africa is one of the countries worse hit by this pandemic. The National HIV Prevalence and Incidence Survey report released by the Human Sciences Research Council (HSRC) of South Africa in 2014 estimated the number of new HIV infections that occurred in South Africa in 2012 at 400,000; raising the proportion of South Africans infected with HIV from 10.6\% in 2008 to $12.2 \%$ in 2012 (Malan, 2014). According to UNAIDS, 2012 estimates, about 5.6 million people were living with HIV in South Africa in 2011; a figure which is the highest compared with that of other countries (UNAIDS, 2012). Yet, the National HIV Prevalence and Incidence Survey conducted by HSRC reported a higher figure of 6.4 million in 2014 (Malan, 2014).

Researches and censuses have shown that women are more vulnerable to contracting the virus compared with their male counterparts (UNAIDS, 2012, 2014). According to UNAIDS, (2008) report, females comprise about 70\% of the world's poor, more than two-thirds of the world's illiterate and more than half (about 52\%) of all the people living with HIV/AIDS. In Sub-Saharan Africa, 58\% of the people living with HIV/AIDS are women (UNAIDS, 2014). Illiteracy and risky sexual behaviours are some of the factors that predispose people to contracting the disease (Kowala-Piaskowska et al., 2010). These three factors are inter-related with the possibility of one resulting in the other and vice-versa. With many cultures against female education while advocating early marriage, the resultant illiteracy and poverty put the female child at a disadvantage and a higher risk of poor health condition including contracting HIV/AIDS (Kowala-Piaskowska et al., 2010).

The informal economy in South Africa is a growing economic sector and a source of employment for those who are marginalized and excluded from formal work opportunities in South African cities and towns for various reasons. One 
main factor is the inability of the government and the formal business sector to provide sufficient employment opportunities to people in the economically active age categories. Street trading, one of the largest sectors of informal work has absorbed many of these people, especially women (Lund, 1998; Chen et al., 2001). It was estimated that in the year 2000, there were about half a million street traders (hereafter referred to as street vendors) in South Africa, and more than $70 \%$ of these were women (International Labour Organization, 2004).

In the Limpopo Province of South Africa, HIV prevalence is still rising. The HIV prevalence among antenatal clients in Limpopo Province, which reflects the prevalence among females of reproductive age, increased from $20.6 \%$ in 2008 to $22.3 \%$ in 2012 (Massyn et al., 2014). Following the same trend is the Vhembe District where HIV prevalence among antenatal clients increased progressively from 13.9\% in 2005 to 17.7\% in 2012 (Massyn et al., 2014), yet, the South African government is still unable to provide drugs for all infected persons (National Department of Health, 2013). More than 13,000 people were newly tested positive for HIV in Vhembe District in 2014. However, the government was able to initiate Intermittent Prophylactic Treatment (IPT) for only 9,759 out of 12,404 eligible HIV positive clients in the district (Department of Health, 2015).

Negative attitudes, the most common of which is stigmatization, have been listed among the factors that hinder the control of HIV (Thanavanh et al., 2013). The United Nations Secretary-General, Ban Ki Moo (2008) observed that many people are afraid to see a doctor for HIV testing or seek treatment if they have the infection for fear of being stigmatized. Sayles et al. (2009) claim that HIV infected individuals are more than four times more likely to report poor access to health care than uninfected ones because of stigmatization from health workers. More than $20 \%$ of HIV-infected people in Nigeria reported a denial of health care because of their status (UNAIDS, 2012). A study conducted by International Labour Organization and the Global Network of people living with HIV (2012) recorded a discriminatory attitude towards people living with HIV as high as 54\% in Malaysia. Holzemer et al.(2009) also reported a high rate of discrimination in five African countries including South Africa.

Araoye (2004) noted in his study among female adolescent street vendors in Nigeria that many of them did not desist from sexual intercourse and some of them even have multiple sexual partners despite the fact that most of them were aware of the sexual transmission mode of the virus. He concluded that their risk perception of the virus was poor. This study was conducted in order to assess the attitudes of female street vendors in Thohoyandou, Vhembe district of South Africa about HIV/AIDS and those infected by it.

\section{Materials and Methods \\ The study design and setting}

A cross-sectional, descriptive design in a quantitative paradigm was employed in this study because it helps to determine cause and effects at the same time, measuring the attitudes of the respondents to HIV and those infected with the virus at the same time. Thohoyandou town was purposively selected for the study because it is the commercial centre of Vhembe District Municipality, surrounded by many rural settlements and rich in maize, tobacco and banana plantations. Most street vendors in Thohoyandou are found trading in Mvuzuludzo Taxi Rank, while others are located in other taxi ranks and some other streets of the town (Arnold, 2013). Most of these are women selling food stuffs (cooked or raw), fruits, vegetables and household items. The major local language is Tshivenda, but there are Tsonga, Sotho and Afrikaans speaking people in a smaller percentage (Siyabonga Africa, 2009).

\section{Population and sampling}

Street vendors in Thohoyandou are registered under four major locations in Thulamela Local Municipality. Participants for this study were selected from the female street vendors (FSV) trading in those locations which are: the Mvuzuludzo taxi rank and its environment, Thulamela taxi rank and its environment, Game shopping mall environment and Phangami mall environment. As at January 2015, 400 female street vendors were registered with the municipality. The Yamane formula $\left\{\mathrm{n}=\mathrm{N} /\left(1+\mathrm{Ne}^{2}\right)\right\}$ was used to arrive at the sample size of 200 . A stratified random sampling technique was employed to select prospective participants.

\section{Data collection and Instrument}

Data were collected using a structured questionnaire which was prepared in English language and translated to Tshivenda. Retranslation studies were carried out to ascertain the accuracy of the instrument. The retranslation showed an accurate translation of the original document to Tshivenda. Both versions were presented to each volunteered participant to choose which one they preferred. The participants who could read and write were given the questionnaires to complete while the researcher and her assistants waited to collect the completed questionnaires. For those who could not read or write, and some who preferred the questions to be read to them, the researcher read the questions to and completed the questionnaires for them. A pretest was conducted using $20 \mathrm{FSV}$ (10\% of sample size) afterwhich some adjustments were made on the instrument. During the main data collection for the study, a total of 220 questionnaires were administered to the respondents and 200 most completed questionnaires were selected for analysis. 


\section{Statistical analysis}

Data obtained were analysed with Statistical Package for the Social Sciences (SPSS), version 20.0. Descriptive statistics were performed on the data and the results were summarised using frequency distribution tables and figures. Chi-square tests were performed to identify the relationships between the sociodemographic characteristics and the attitudes of the participants to HIV and those infected. A p-value of less than 0.05 was set to be statistically significant.

\section{Ethics and Consent}

Ethical approval was obtained from the University of Venda Health, Safety and Research Ethics Committee (SHS/15/PH/06/1803). Permission to conduct the study was obtained from the Department of Health, Vhembe District and the Manager of Thulamela Local Municipality. An information letter with detailed explanation of the purpose and method of the study was given to each participant to read (or read and explained to her) before being given the consent form to sign or thumbprint and afterwards the questionnaires were administered to them. The information letter also contains other ethical issues like voluntary participation, informed consent, the right to withdraw, confidentiality, anonymity and minimization of risk of harm to participants.

\section{Results}

\section{Sample Characteristics}

The sociodemographic characteristics of the respondents are presented in Table 1 below.

Table 1: Socio-demographic Characteristics of the Participants.

\begin{tabular}{|c|c|c|}
\hline CHARACTERISTIC & $\mathbf{n}$ & $\%$ \\
\hline \multicolumn{3}{|c|}{ AGE (YEARS) } \\
\hline$<20$ & 6 & 3.0 \\
\hline $20-30$ & 52 & 26.0 \\
\hline $31-40$ & 59 & 29.5 \\
\hline$>40$ & 83 & 41.5 \\
\hline TOTAL & 200 & 100 \\
\hline \multicolumn{3}{|c|}{ MARITAL STATUS } \\
\hline Single & 93 & 46.7 \\
\hline Married & 69 & 34.7 \\
\hline Separated & 14 & 7.0 \\
\hline Divorced & 8 & 4.0 \\
\hline Widowed & 15 & 7.5 \\
\hline Total & 199 & 100 \\
\hline \multicolumn{3}{|c|}{ LEVEL OF EDUCATION } \\
\hline None & 8 & 4.1 \\
\hline Primary & 22 & 11.2 \\
\hline Secondary & 121 & 61.4 \\
\hline Tertiary & 46 & 23.3 \\
\hline Total & 197 & 100 \\
\hline \multicolumn{3}{|c|}{ AVERAGE INCOME PER WEEK } \\
\hline$<\mathrm{R} 500$ & 91 & 65.0 \\
\hline $\mathrm{R} 500-\mathrm{R} 1000$ & 32 & 22.9 \\
\hline$>1000$ & 17 & 12.1 \\
\hline Total & 140 & 100 \\
\hline \multicolumn{3}{|c|}{ NUMBER OF DEPENDANTS } \\
\hline None & 24 & 12.8 \\
\hline $1-3$ & 72 & 38.3 \\
\hline$>3$ & 92 & 48.9 \\
\hline Total & 188 & 100 \\
\hline
\end{tabular}

\section{Attitide towards voluntary HIV testing}

Almost all the participants $(n=181,90.5 \%)$ indicated that they would accept to do a voluntary HIV test. The reasons for decline given by the other respondents are presented in figure 1 . 
Olaniyi et al., Afr., J. Infect. Dis. (2017) 11 (2): 17-23

https://doi.org/10.21010/ajid.v11i2.3

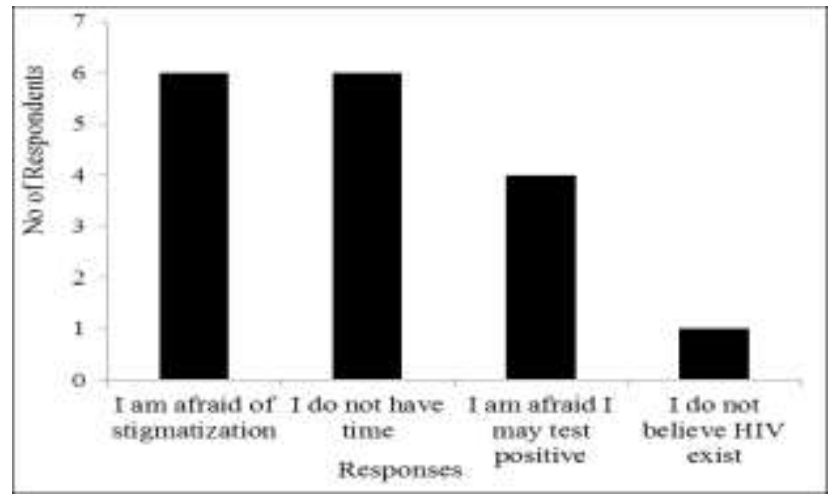

Figure 1: Given reasons for not accepting to do a voluntary HIV test

\section{Attitudes towards taking antiretroviral drugs (HAART) in pregnancy}

A total of 151 participants responded to this question out of which $115(57.5 \%)$ indicated that they would take the drugs if they were tested positive during antenatal visit; 36 (18\%) said they would not take the drugs while 49 (24.5\%) avoided answering the question.

\section{Attitudes towards transactional sex}

Most participants $(n=177,88.5 \%)$ responded that they will not have sex in exchange for money (Figure 2).

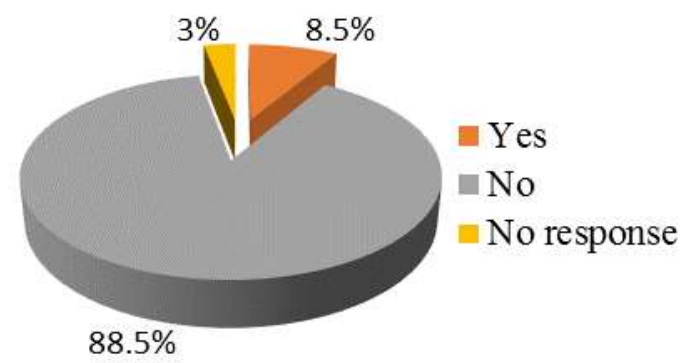

Figure 2: Will you have sex in exchange for money?

\section{Attitudes towards those infected with HIV}

Almost all the respondents $(91.0 \%)$ reported that they can stay in the same house with a relative or friend who tested HIV positive (Figure 3).

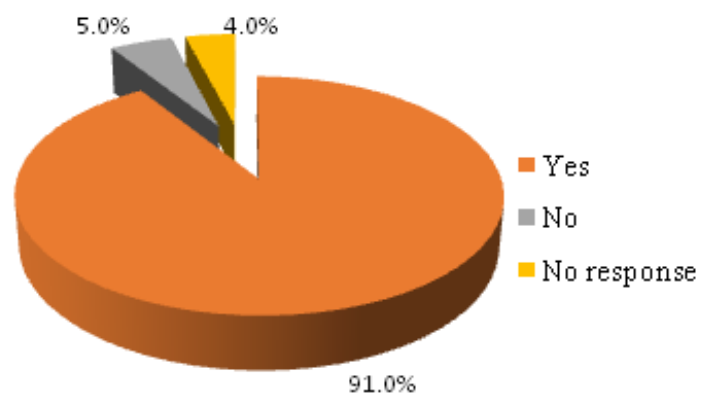

Figure 3: If a relative or friend is tested positive, can you stay in the same house with him or her?

\section{Discussions}

Almost all the participants in this study indicated that they would accept to do a voluntary HIV test. The high number of the participants who would accept to do a voluntary HIV test found in this study is highly commendable. It is a great improvement on the HSRC's report on the National HIV Prevalence, Incidence and Behaviour Survey done in 
South Africa in 2014 in which only about $76 \%$ of the participants agreed to be tested for the virus (Malan, 2014). This shows that many more people have developed a positive attitude towards testing for HIV.

The reasons given by the few who declined the test ranged from fear of stigmatization, not having time to go for the test and fear of testing positive. Only one participant claims that she does not believe that HIV exists, while two others who also said they would decline the test did not give any reasons for their response. Stigmatization has remained a big problem in the HIV/AIDS debate and a major reason why many still maintain a negative attitude towards being tested for the virus. A high rate of discrimination against HIV positive people has been reported in five African countries including South Africa (Holzemer et al., 2009). Stigmatization is exhibited at every level, even among the health professionals where it is least expected (UNAIDS, 2012; Ban, 2008; Sayles et al., 2009). An underlying fear of subsequent stigmatization may also be the reason for those who claimed they do not have time to go for the test and those who said they are afraid of testing positive.

Highly Active Antiretroviral Therapy (HAART) are known to retard the progression of HIV to AIDS. Taking antiretroviral drugs in pregnancy is a way of reducing the menace of mother-to-child transmission (MTCT) of HIV. However, only 115 of the participants in this study responded to the question about taking the drugs if they are tested positive during antenatal visit. This is an indication that the respondents were not positively inclined to the benefits of taking antiretroviral drugs in pregnancy if they are tested positive and the possible consequences of not doing so. Those who left the question unanswered (about 24.5\%) may be regarded as avoiding such a question because they do not even want to think of being tested positive or they might not have a good understanding of the benefits of taking the drugs during pregnancy. Furthermore, only $76.2 \%$ of those who answered the question said they will take antiretroviral drugs if they are tested positive to HIV during antenatal visit; this response is worrisome because more than $90 \%$ of cases of paediatrics' HIV are from vertical transmission, which can be reduced if an infected mother takes antiretroviral drugs in pregnancy (Muula, 2000; Gayle and Hill, 2001).

Though, a negligible number of the participants answered in the affirmative that they would have sex for money, however, more street traders might be involved in such an act, but refuse to publicly admit to it due to the sensitive nature of the question and the societal stigmatization attached to such a behavior. Some respondents to whom the questions were being read felt offended to be asked such a question and refused to give an answer. Previous researches have however shown that many female street traders are involved in transactional sex to support their meager income as many of them are bread-winners in their homes (Lee, 2004; Roever, 2014). The fact that most of the participants in this study have 3 or more dependants and yet earn less than R500 every week on the average (Table 1) makes it suspiscious that at least some of those who said they can not have sex in exchange for money might actually be involved in the act to make ends meet.

Almost all the respondents $(91.0 \%)$ reported that they can stay in the same house with a relative or friend who tested HIV positive. This finding is in consonance, with some improvements on the report of the Department of Health, Medical Research Council (2007) of South Africa where 85\% of women said they would be willing to care for an HIV - infected family member at home. This shows an increasingly positive attitude towards those who are infected with HIV.

The level of education of the respondents was found to be significantly associated with their attitudes towards HIV and those infected with the virus $(\mathrm{p}=0.000)$ implying that the more educated a woman is, the more likely she would have a positive attitude towards the virus and those infected by it. Unnikrishnan et al. (2010) also recorded a similar finding in their study in Coastal Karnataka where respondents with less than secondary school education had discriminatory attitudes towards the people infected with HIV. This suggests that women education, which is discouraged in many African cultures should rather be encouraged to reduce the menace of HIV/AIDS to the bearest minimum.

\section{Conclusions}

With increasing availability of HIV information from the media, handbills and posters, and in many local languages including Tshivenda, many people including the female street vendors in Thohoyandou have developed a satisfactory level of acceptable attitudes towards HIV and those who are infected with it. However, the prevailing problem of stigmatization is yet to be solved. Many female street vendors in Thohoyandou seem not to know the importance of using antiretroviral drugs if tested positive for HIV in pregnancy, however, their saying "no" to the drugs may also be a way of hiding their HIV statuses from relatives for fear of stigmatization as many of those who will not accept to do the test indicated. This attitude definitely needs to be improved upon. HIV information providers and health workers alike should provide health education to women about the importance of taking antiretroviral drugs if tested positive in pregnancy to reduce the chances of the unborn baby getting infected. They should also provide the necessary support for infected pregnant women to take antiretroviral drugs during pregnancy and delivery to reduce the the incidence of mother-to-child transmission of HIV. HIV infected women should not be stigmatized in any way by health workers. Female education should be encouraged as it has a significant impact on the attitude towards HIV/AIDS.

\section{Acknowledgements}

The authors wish to thank the Research and Publication Committee (RPC) of the University of Venda for funding this study and the female street vendors who volunteered and participated in the study. 


\section{References}

1. Araoye, M.O. (2004). Female adolescent hawkers in Nigeria: HIV/AIDS-related knowledge, attitudes and behavior. J. Community Med. Prim. Health Care, 16: 23-29.

2. Arnold, N. M. (2013). The role of Thulamela Municipality in creating an enabling environment for informal vendors in Thohoyandou. J. Manage. Admin, 11: 1, 116-135.

3. Ban, K.M. (2008). The stigma factor. The Washington Times, $6^{\text {th }}$ August, 2008.

4. Chen, M. A., Jhabvala, R. and Lund, F. (2001). Supporting workers in the informal economy: a policy framework. Paper prepared for the ILO task force on the informal economy, pp 4-15. Geneve, Switzerland.

5. Department of Health, Medical Research Council, OrcMacro. (2007). South Africa demographic and health survey 2003 full report. Pretoria: Department of Health.

6. Department of Health, Vhembe District (2015). Vhembe district health statistics. Thohoyandou, South Africa.

7. Fowler, N. (2014). HIV remains a global health problem, thanks to ignorance and prejudice. The Guardian, $8^{\text {th }}$ June, 2014.

8. Gayle, H. D; Hill, G. L. (2001). Global impact of Human Immunodeficiency Virus and AIDS. Clin. Micro. Rev, 14, 2, 327-335.

9. Global Network of people living with HIV and International Labor Organization. (2012). Evidence brief: Stigma and discrimination at work: findings from the people living with HIV Stigma Index, pp 1-23. Amsterdam, Netherlands

10. Holzemer, W.L., Makoae, L.N., Greeff, M., Dlamini, P.S., Kohi, T.W., Chirwa, M.L. and Uys Y.R. (2009) Measuring HIV stigma for PLHAs and nurses over time in five African countries. Sahara J, 6: 2, 76-82.

11. International Labour Organization.(2004). Street Vendors and their Associations in South Africa, pp 3-24, Geneva, Switzerland.

12. Kowala-Piaskowska, A., Mania, A., Barałkiewicz, G., Żeromski, J. and Mozer-Lisewska, I. (2010). Woman living with HIV/AIDS and her child: epidemiological data. HIV AIDS Rev, 9: 3, 72-78.

13. Lee, S. (2004). Assessing the vulnerability of women street vendors to HIV/AIDS - A comparative analysis of Uganda and South Africa. Health Economics and HIV/AIDS Research Division. Available online: http://www.eldis.org/static/DOC16577.htm [Accessed 12/07/2015].

14. Lund F. (1998). Women Street Traders in South Africa: A Synthesis of Selected Research Findings, CSDS Research Report No. 15, 1998, School of Development Studies, University of Natal, Durban, South Africa.

15. Malan, M. (2014). SA has highest number of new HIV infections worldwide - Survey. Mail \& Guardian, $1^{\text {st }}$ April, 2014.

16. Massyn, N., Day, C., Peer, N., Padarath, A., Barron, P. and English, R., Eds. (2014). District Health Barometer 2013/14,3 $3^{\text {rd }}$ Ed.; Health Systems Trust: Durban, South Africa, pp. 114-120.

17. Muula, A.S. (2000). Tackling HIV/AIDS in Africa - another perspective. Africa Health, 23: 1, 5-6.

18. National Department of Health. (2013). Annual report 2012/2013. Department of Health: Pretoria, South Africa.

19. Roever, S. (2014). Informal Economy Monitoring Study Sector Report: Street Vendors. Cambridge, MA, USA: WIEGO.

20. Sayles, J., Wong, M., Kinsler, J., Martins, D. and Cunningham, W. (2009). The association of stigma with self-reported access to medical care and antiretroviral therapy adherence in persons living with HIV/AIDS. J. Gen. Intern. Med, 24: 10, 1101-1108.

21. Siyabonga Africa, Venda (2009). Available online: http://www.krugerpark.co.za/africa_venda.html (accessed on 3 March, 2015). 
Olaniyi et al., Afr., J. Infect. Dis. (2017) 11 (2): 17-23

https://doi.org/10.21010/ajid.v11i2.3

22. Thanavanh, B., Harun-Or-Rashid, M., Kasuya, H. and Sakamoto, J. (2013). Knowledge, attitudes and practices regarding HIV/AIDS among male high school students in Lao People's Democratic Republic. J. Int. AIDS Soc, $16: 17387$.

23. The Joint United Nations Programme on HIV and AIDS. (2014). Fact sheet 2014 global statistics, pp1-8, Geneva, Switzerland.

24. The Joint United Nations Programme on HIV and AIDS. (2008). Report on the global AIDS epidemic: executive summary, Geneva, Switzerland.

25. The Joint United Nations Programme on HIV and AIDS. (2012). World AIDS Day Report, pp1-212, Geneva, Switzerland.

26. Unnikrishnan, B., Prasanna, P. M., Rekha, T. and Reshmi, B. (2010). Awareness and attitudes of the general public towards HIV/AIDS in Coastal Karnaka. Indian J. Community Med, 35:1, 142-146. 